\title{
Pseudoelastic Deformation of CuAlMn Single Crystals
}

\author{
J. Dutkiewicz, M. Bartsch*, S. Miura**, U. Messerschmidt* and H. Kato**
}

Institute of Metallurgy and Materials Science, Polish Academy of Sciences, 30-059 Krakow, ul. Reymonta 25, Poland

* Max-Planck-Institute of Microstructure Physics, Halle Weinberg 2, D-06120, Germany

** Department of Engineering Science, Faculty of Engineering, Kyoto University, Kyoto 606-01, Japan

\begin{abstract}
Martensitic transformation associated with a tensile deformation of CuAlMn single crystals in [100] direction was studied using in-situ transmission electron microscopy. Stress/strain curves obtained during pseudoelastic deformation of microscopic samples were slightly different from bulk ones due to martensite formation in the stage of stress increase and a permanent deformation during the first cycle. Individual needles of $2 \mathrm{H}$ martensite were formed already in the early deformation stage. They were growing during stress increase, joining together into large plates. At later deformation stages 18R martensite was formed usualy in stacks of single plates. Following crystallographic relationship between parent and martensitic phases was observed: [001] $\beta_{1} \|[010] \gamma^{\prime}, \beta^{\prime}$ and $[110] \beta_{1} \|[001] \gamma^{\prime}, \beta^{\prime}$. At a high stress concentration near crack tips, $\alpha^{\prime}$ martensite of $3 R$ lattice was observed. Identification of martensite structure was very often not possible there, due to an extremely high random stacking faults density.
\end{abstract}

\section{INTRODUCTION}

Martensitic transformation associated with deformation was most intensively studied in CuAlNi alloys [1-3], where multistage stress strain curves corresponding to a successive martensite to martensite transformation has been reported [2,3]. Similar phenomena were found during pseudoelastic deformation in CuAlFe [4] and CuAlZn [5] alloys. Structure of martensite was identified using X-ray diffraction. Application of in-situ high voltage electron microscope (HVEM) tensile experiments of CuAlFe single crystals [6] allowed to distinguish the morphology of $18 \mathrm{R}$ and $2 \mathrm{H}$ martensites, their crystallographic relationship with a matrix and a ledge mechanism of martensite growth.

Shape memory properties of CuAlMn alloys were demonstrated several years ago [7] being sensitive to a pretraining treatment [8]. Recent investigations of stress strain behaviour associated with the thermoelastic martensitic transformation in CuAlMn single crystals have shown similarities to that of CuAlNi with multistage stress-strain curves [9]. In the present study single crystals of (001)[100] orientation of CuAlMn alloys were studied using in-situ HVEM tensile deformation. 


\section{EXPERIMENTAL PROCEDURE}

Two alloys Cu23at\% Al 7at \% Mn (1) and Cu20.8at\% Al 9.5at\% Mn (2) were cast in an induction furnace from $4 \mathrm{~N}$ purity $\mathrm{Cu}$ and $\mathrm{Al}$ and $3 \mathrm{~N}$ purity of $\mathrm{Mn}$. Single crystals were prepaired using the Bridgman method. The single crystals were quenched from $850^{\circ} \mathrm{C}$ into water at $50^{\circ} \mathrm{C}$. Martensitic transformation temperatures were determined using DSC Du Pont 9000 thermal analyser. Specimens for in-situ straining experiments were cut in a form of thin sheets of size $0.1 \times 3 \times 8 \mathrm{~mm}$ of (001)[100] orientation using a diamond saw. Then, a two stage electrolytic polishing was applied, first using platinium mask of size $1 \times 2$ $\mathrm{mm}$ in $\mathrm{CrO}_{3}$ saturated $\mathrm{H}_{3} \mathrm{PO}_{4}$ to create a flat dimple in the center, then a final electropolishing in $1 / 3 \mathrm{HNO}_{3}$ $2 / 3 \mathrm{CH}_{3} \mathrm{OH}$ solution at $-30^{\circ} \mathrm{C}$ until perforation. In-situ tensile experiments were performed using JEOL $1000 \mathrm{kV}$ electron microscope equipped with a tensile stage designed by Messerschmidt and Appel [10].

\section{RESULTS AND DISCUSSION}

Characteristic transformation temperatures determined for alloy 1 were: $M_{s}=14^{\circ} \mathrm{C}, A_{s}=40^{\circ} \mathrm{C}$ and for alloy $2, M_{s}=-30^{\circ} \mathrm{C}$ and $A_{f}=-34^{\circ} \mathrm{C}$. Since $A_{f}$ of alloy 1 lies above $R T$ it does not show superelastic behaviour at RT. Fig. 1 shows typical stress strain curves obtained during tensile deformation at various temperatures up to $6 \%$ strain. The stress/strain curve (a) at $17^{\circ} \mathrm{C}$ i.e below $A_{f}$ is smooth, contrary to (b) which shows large serrations. They result from the formation and propagation of $\gamma^{\prime}(2 \mathrm{H})$ martensite. Increasing the tensile temperature to $25^{\circ} \mathrm{C}$ (d) one observes two plateaus due to formation of two types of
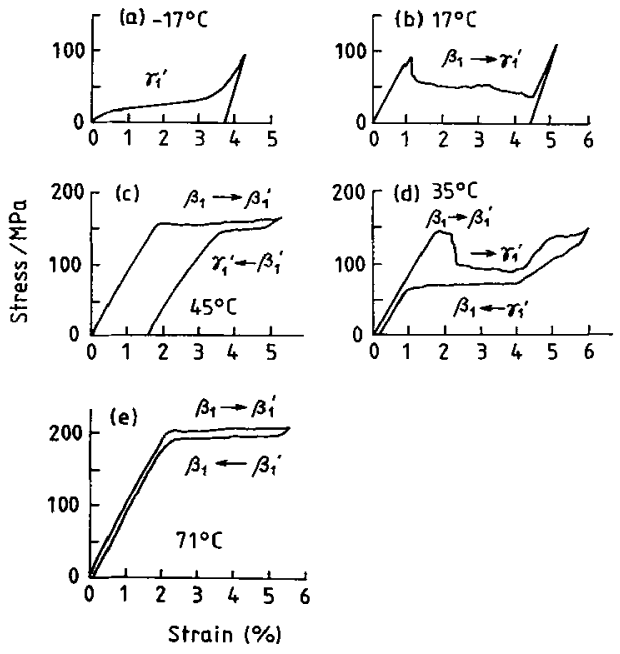

Fig. 1 Stress/strain curves of alloy 1 single crystals in [100] direction at various temperatures

martensite i.e. $\beta^{\prime}(18 \mathrm{R})$ and $\gamma^{\prime}(2 \mathrm{H})$ during stress increase. Such a curve was not observed by Oishi and Brown [2] during tensile deformation of CuAlNi single crystals. At $71^{\circ} \mathrm{C}$ (e) a typical pseudoelastic tensile 
curve can be seen. Deformation proceeds by increasing density of fine plates as observed by optical microscopy [12].

Fig. 2 shows a sequence of HVEM in-situ load/elongation curves obtained from a single crystal of alloy 2 at (001)[100] (sample surface/tensile direction) orientation. The first curve shows only a small shape recovery due to inhomogeneous deformation in thin areas where plastic deformation of martensite takes place. Thus, it was difficult to observe shrinking of martensitic plates during stress release in the first deformation cycle. As compared to bulk samples [9], martensite formed much earlier in the present study, already in the stage of stress increase.

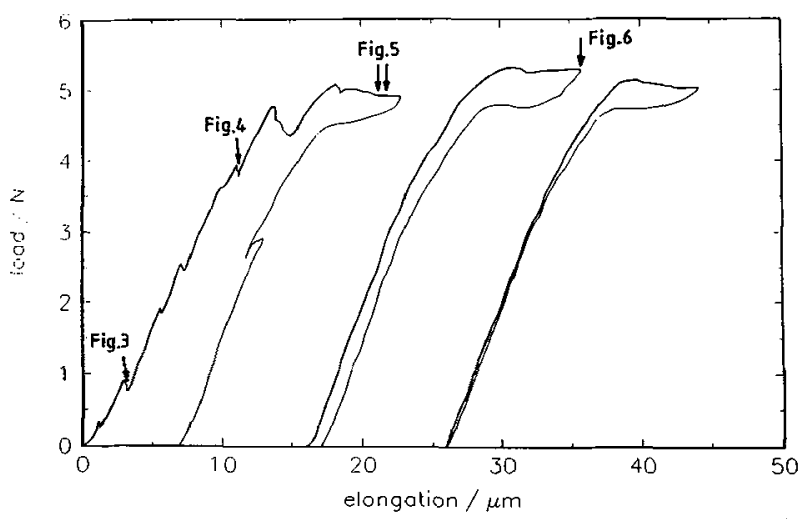

Fig. 2 Sequence of HVEM in-situ load/elongation curves obtained during deformation of alloy 2 single crystal at (001)[100] orientation.

Fig. 3 shows a transmission electron micrograph (a) taken at the initial period of deformation where a mechanism of martensite growth can be observed. Several needles grow in [120] $\beta_{1}$ direction joining together to form one large plate. The following crystallographic relationship can be determined from the electron diffraction pattern (Fig.3b), [010] $\gamma^{\prime} \|[001] \beta_{1}$ and $[001] \gamma^{\prime} \|[110] \beta_{1}$. Most of the martensitic plates formed in the early stages of deformation were identified as $2 \mathrm{H}$.

Fig. 4 shows a set of $18 \mathrm{R}$ needles growing in $[120] \beta_{1}{ }^{\prime}$ direction much more densely packed than in the case of $2 \mathrm{H}$ needles. They are formed at a load close to that corresponding to the plateau in the deformation curve. The following crystallographic relationship was found $[001] \beta_{1} \|[010] \beta_{1}^{\prime}$ and $[110] \beta_{1} \|[0018] \beta^{\prime}$. 
Fig. 5 shows a sequence of a video recording during the in situ straining experiment. One can see nucleation of a small plate ( $5 \mathrm{a}$ marked by the arrow) at a triple point of two plates and the matrix. At a load increase several parallel needles appear, forming at the same place a stack (like that visible in Fig.3).
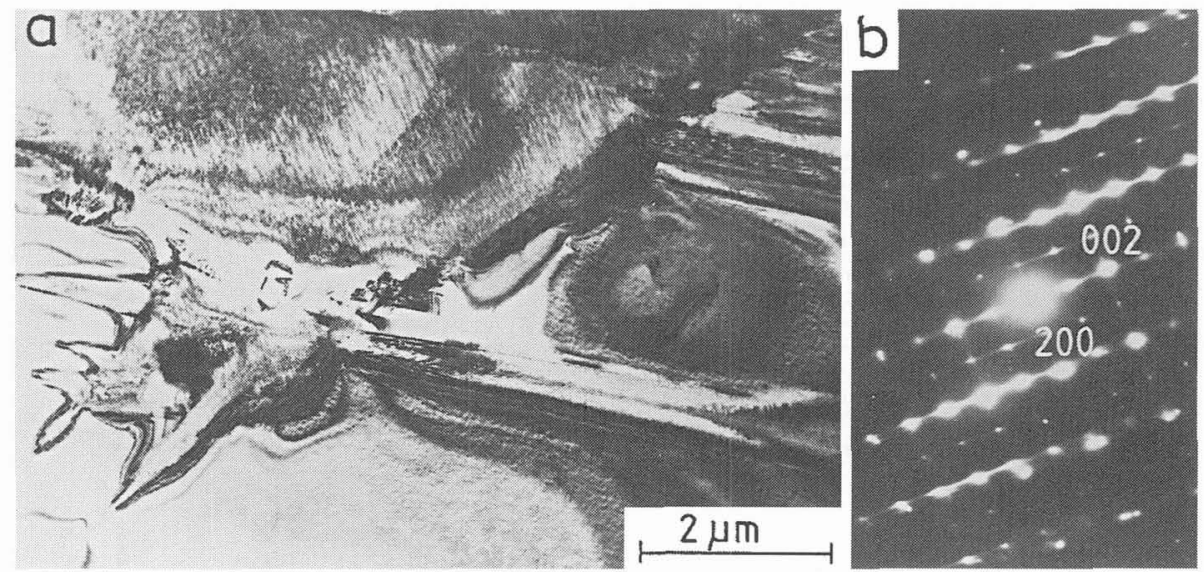

Fig.3(a) Transmission electron micrograph formed at the initial stage of load increase (see Fig.2), (b) Selected area diffraction pattern (SADP)

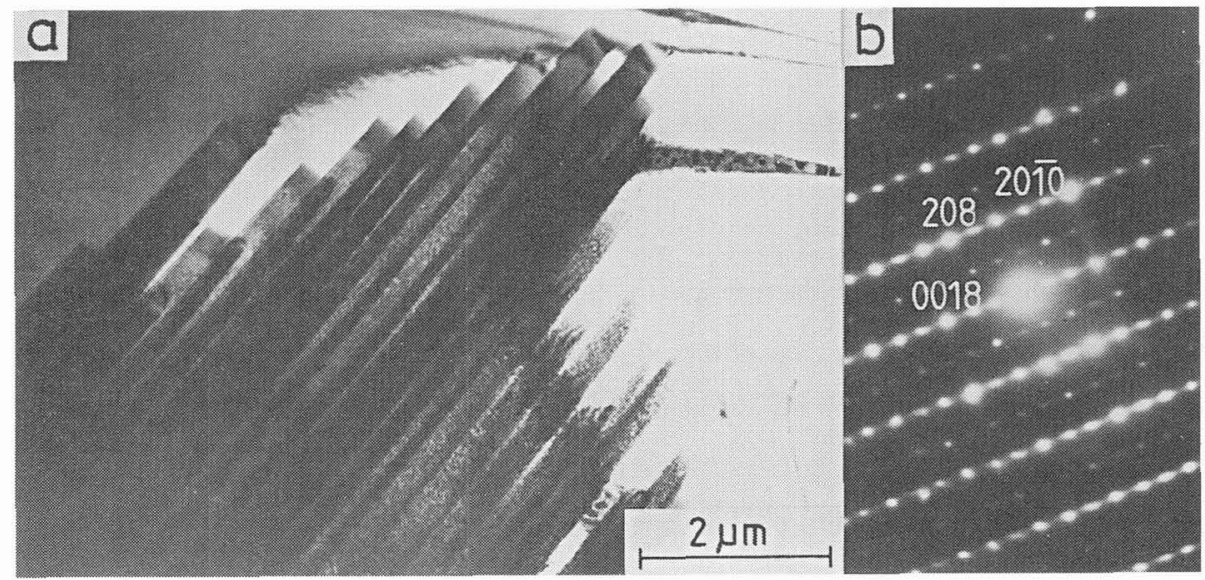

Fig. 4 Transmission electron micrograph (a) taken at the final stage of load increase (see Fig.2), (b) SADP. Fig.3). Later on they join with one on the left side, existing from the beginning, to build up a large plate (Fig.5d). A boundary between the new and an old plate results most probably from a difference in a 
stacking order, most probably of $18 \mathrm{R} / 2 \mathrm{H}$ type. Several of them were observed to form during in-situ deformation. Needles visible at the right bottom corner of the micrographs are a part of a growing frontier of a lower plate into the matrix, increasing their length during increasing load (fig5.a-b). However, when another plate forms from the upper side a complicated shape of a boundary becomes unstable and plates start to shrink (Fig. $5 \mathrm{c}-\mathrm{d}$ ) decreasing the energy of a boundary.
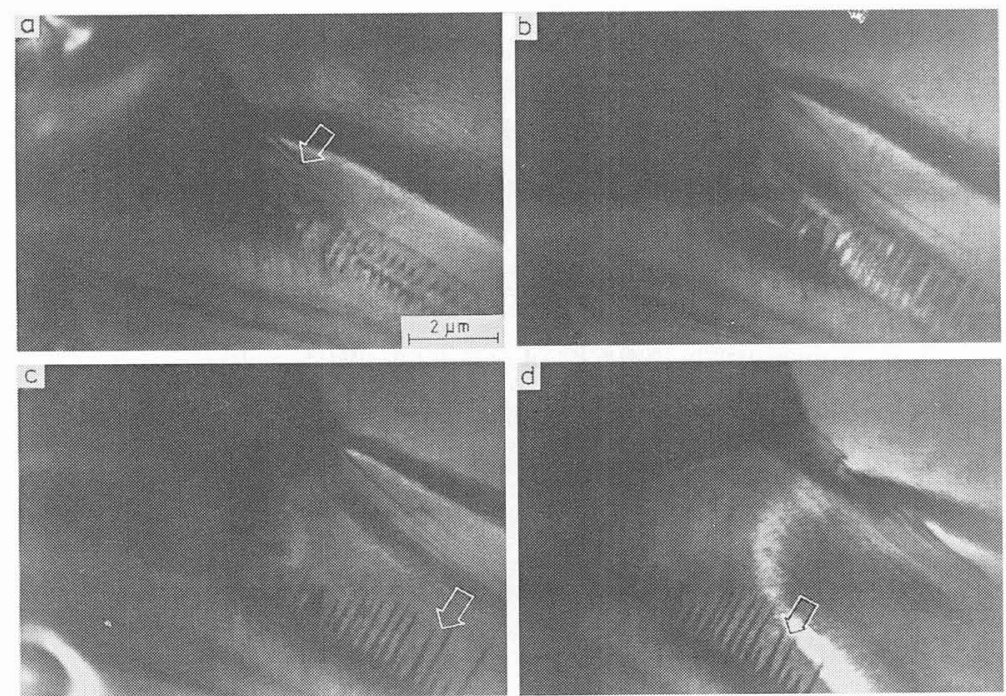

Fig. 5 Sequence of micrographs chosen from a video recording during in-situ tensile experiment at a final part of plateau (see Fig. 2).

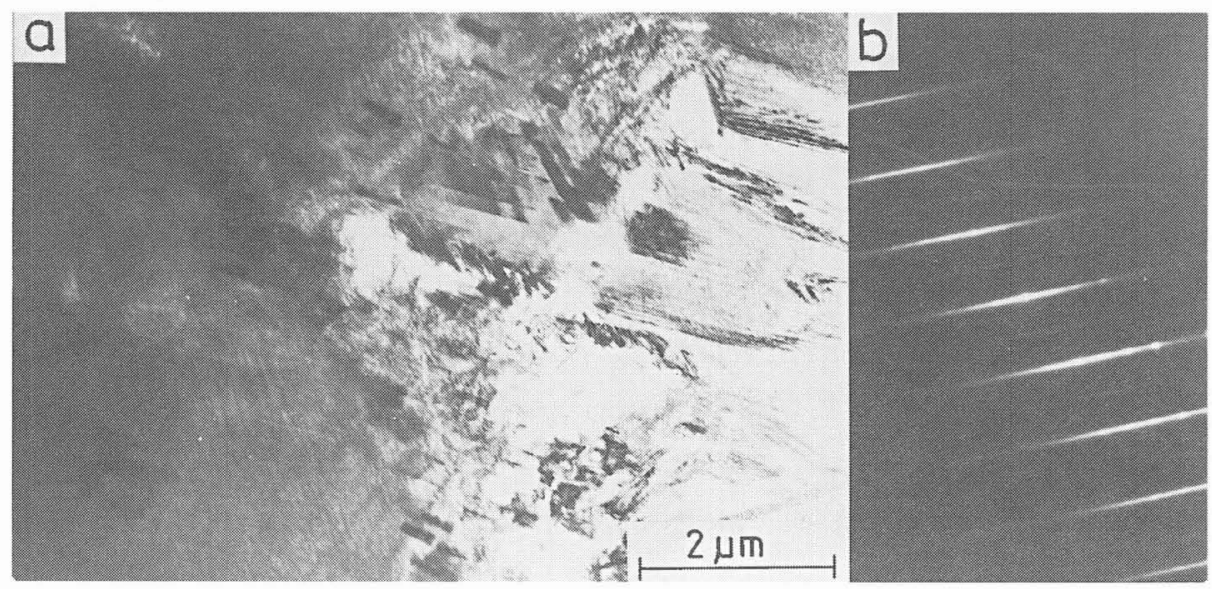

Fig.6 TEM micrograph (a) taken during second deformation cycle showing extremely high random stacking fault density. (b) SADP. 
Last micrograph (Fig.6.a) shows a microstructure of a plate formed in the second cycle (see Fig.2). It shows an extremely high random stacking fault density (including non-basal faults) making it impossible to identify plate structure from the diffraction pattern (Fig.6.b) since individual reflections are hidden within a streaks of high intensity. Since such a situation was often observed near cracks at the edge of the foil it is most probably caused by a plastic deformation of the martensite.

\section{CONCLUSIONS}

1. The stress/strain behaviour of CuAlMn single crystals is very similar to that of CuAINi and CuAlFe showing multistage stress/strain curves due to formation of $2 \mathrm{H}$ and $18 \mathrm{R}$ deformation martensites.

2. In samples deformed in-situ during HVEM observation, at first individual needles of $2 \mathrm{H}$ martensite were observed, joining later with the other ones and forming a large plates. At later deformation stages $18 \mathrm{R}$ martensite needles were formed, usualy in stacks of individual plates.

3. Following crystallographic relationship between the parent and martensitic phases was observed [001] $\beta_{1}$ $\|[010] \gamma_{1}^{\prime}, \beta_{1}^{\prime}$ and $[110] \beta_{1} \|[001] \gamma_{1}^{\prime}, \beta_{1}^{\prime}$.

4. At high stress concentration, like near cracks at a foil edge very high random stacking fault density was observed making impossible identification of a periodic stacking structure of a martensite

\section{REFERENCES}

[1] Rachinger W.A., Br. J. Appl. Phys. 9, (1958) 250-256

[2] Oishi K. and .Brown L.C, Metall. Trans. 2, (1971) 1971-1977

[3] Otsuka K., Wayman C.M., Nakai K., Sakamoto H. and Shimizu K., Acta Metall., 24 (1976) 207-226

[4] Martynov V.V., Enami K., Tkachenko A.V., Khandros L.G., Dokl. Akad. Nauk SSSR 258 (1981) 608

[5] Saburi T., InadaY., Nenno S. and Hori N, J.de Physique C4 43 (1982) 633-639

[6] J.Dutkiewicz, V.V.Martynov, U.Messerschmidt, J.Mater. Sci 24 (1989) 3904-3912

[7] Kuporev A.L. and.Khandros L.G, Phys. Metals Metallogr., 34 (1972) 213-219

[8] Mellor B.G.,Hernaez J. and Lopez del Castillo C., Scripta Met., 20 (1986) 839-841

[9] Kato H., Dutkiewicz J. and Miura S. Acta Metall. Mater., 42 (1994) 1359-1365

[10] Messerschmidt U. and .Appel F, Ultramicroscopy 1 (1976) 223-226

Acknowledgements: J.Dutkiewicz acknowledges support from the Research grant No 308489101 from the Polish Committee for Scientific Research, and a scholarship from the Japan Society for the Promotion of Science and from the Deutsche Akademische Austausch Dienst. 